\title{
CASE STUDY ON DESIGNING ADAPTATION MEASURES FOR STORM SURGE DISASTERS ALONG INNERMOST COAST OF ARIAKE SEA, JAPAN
}

\author{
Yoshihiko Ide, Kyushu University, ide@ecoh.co.jp \\ Noriaki Hashimoto, Kyushu University, hashimoto-n@civil.kyushu-u.ac.jp \\ Masaru Yamashiro, Kyushu University, yamashiro@civil.kyushu-u.ac.jp \\ Mitsuyoshi Kodama, Kyushu University, kodama@civil.kyushu-u.ac.jp
}

\section{INTRODUCTION}

Based on the Japanese governmental adaptation plan against the influence of climate change, the local governments promptly have to design such measures. We focused on the vulnerability of storm surge disasters along the innermost coast, Saga Plain, of the Ariake Sea (Fig. 1a) since most of the area is below sea level. We present our experiences of the attempts to design adaptation measures from various approaches as collaborative research with members of Saga Prefecture. Figure $1 \mathrm{~b}$ shows a meeting with members of the prefecture.
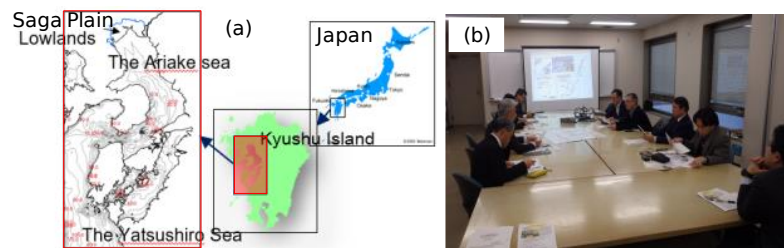

Figure 1 - (a) Map of the Ariake Sea and Saga Plain, and (b) Meeting with members of Saga Prefecture

\section{DEVELOPMENT OF BIAS CORRECTION METHOD OF} FUTURE CLIMATE DATA

Climate change prediction is conducted with Atmospheric Global Climate Model (AGCM) developed in Program for Risk Information on Climate Change, Japan. Figure 2 shows cumulative distribution functions (CDFs) of central typhoon pressure of both observation and AGCM in present and future. Due to climate change, typhoon intensity increases in the future (red) relative to the present (blue). AGCM has certain bias as can be seen from difference between its CDFs in present (blue) and observed one (black). Hence, we developed a suitable bias correction method for AGCM and evaluated future typhoon risks properly.

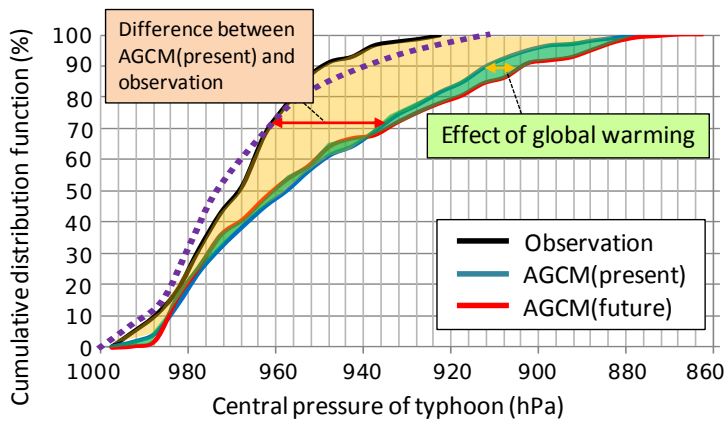

Figure 2 - CDFs of typhoon pressure of observation (black) and AGCM in present (blue) and future (red)

DEVELOPMENT OF BIAS CORRECTION METHOD OF WIND FIELD COMPUTED BY EMPIRICAL TYPHOON MODEL

Accuracy of inundation simulated by storm surge model is greatly influenced by external forces at the surface (e.g., wind stress of typhoon, etc.). The advanced mesoscale meteorological models (e.g., Weather Research and Forecasting model (WRF)) give accurate wind fields which take into account topographical features (Fig.3a). However, the WRF requires huge computational cost and it is difficult to simulate virtual typhoons. Therefore, it is not suitable for our present study in which we deal with large number of virtual typhoons. On the other hand, the empirical typhoon model can simulate virtual typhoons with ease, though the accuracy is lower than WRF (Fig.3b). Hence, correction coefficients were estimated by comparing the wind fields calculated by the typhoon model and those by WRF. Wind fields of the typhoon model corrected with the coefficients were used as external forces in the storm surge inundation simulations. Figure $3 \mathrm{c}$ shows an example where the corrected wind field moderately agrees with WRF (Fig 3a).

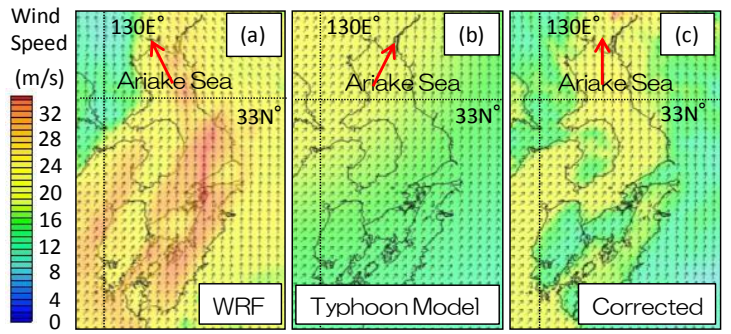

Figure 3 - Wind fields of (a) WRF, (b) the typhoon model and (c) corrected wind

\section{EXAMPLES OF INUNDATION SIMULATIONS UNDER} VARIOUS ADAPTATION MEASURES

We conducted various storm surge inundation simulations to evaluate the effects of the adaptation measures for the disasters. Figure 4 shows that (a) simulated maximum inundation depth without dike break under a severe typhoon and (b) the difference between the simulated depths with and without dike break caused by water overflows. A wide area in the Saga Plain is inundated even without dike break. The depth of maximum inundation simulated with a dike break increases. Especially, in the Shiroishi area, the depth increases more than $1 \mathrm{~m}$.

We investigated the effects of a discharge pump and the timing of the opening or closing of floodgates on inundation disaster, and found the most dangerous route of typhoons and conducted many other examinations for adaptation measures.
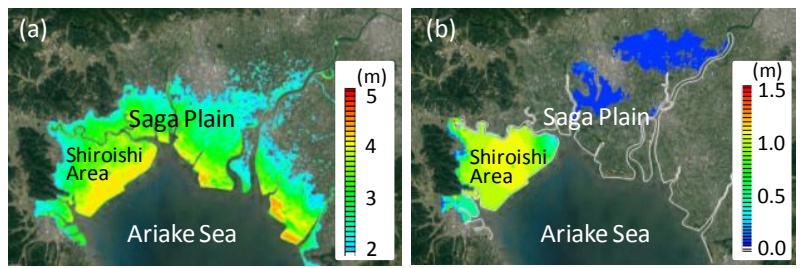

Figure 4 - (a) Simulated maximum inundation depth without dike break. (b) The difference between the simulated depths with and without dike break 